\title{
EVALUATION OF A RAPID METHOD USED FOR DETECTION OF ADDED SULPHATE IN MILK
}

\author{
CHAUDHARI. P. $\mathbf{R}^{\mathbf{1}}$ \& APARNATHI. K. $\mathrm{D}^{\mathbf{2}}$ \\ ${ }^{I} M$. Tech. Scholar, Department of Dairy Chemistry, SMC College of \\ Dairy Science, Anand Agricultural University, India \\ ${ }^{2}$ Professor \& Head of department, Department of Dairy Chemistry, SMC College of \\ Dairy Science, Anand Agricultural University, India
}

\begin{abstract}
In the present study, different qualitative tests used for detection of adulterants in milk were evaluated for (1) sensitivity (LoD), and (2) interference of common preservatives in the detection of adulterants in milk. Sulphate can be detected in milk, using barium chloride test and for checking the sensitivity of test samples of milk were prepared by addition of sodium sulphate at the rate of $0.00,0.01,0.025,0.05,0.10,0.15$ and 0.20 ( $\mathrm{g}$ per $100 \mathrm{ml}$ milk). For each adulterant and each qualitative test, five replications were conducted. For detection of sulphate in milk, only barium chloride test is reported. No variation was reported in literature for barium chloride test. The presence of hydrogen peroxide or formaldehyde had no effect on this test, but sodium hydroxide had a negative effect on the test.
\end{abstract}

KEYWORDS: Adulteration, Barium Chloride Test, Level of Detection, Sulphate \& Qualitative Test

Received: Jun 15, 2017; Accepted: Aug 24, 2017; Published: Sep 28, 2017; Paper Id.: IJASROCT201745

\section{INTRODUCTION}

The practice of adulteration of milk is as old as history and is one of the major problems that stands against the progress of the dairy industry in India; as well as also affect on the quality of milk and milk products. Adulteration may be defined as any addition or subtraction of the legally prohibited substances, into or from a more valuable genuine product (Wilhelmsen, 2004). Profit margins in food production are usually relatively narrow, compared with other industrial sectors such as the pharmaceutical industry. Therefore, it is not surprising that, attempts by some unscrupulous suppliers to maximize revenues by counterfeiting and adulterating practices are a concomitant phenomenon of the food trade (Schieber, 2008). According to the national survey on milk adulteration 2011, over 68 percent of milk in the country did not conform to the standards, set by the Food Safety and Standards Authority of India (FSSAI, 2011). The most widely practiced approach of adulterating milk, is to mix water in it and subsequently adding urea, sulphate and similar compounds to raise solid not fat (SNF). Thus, normally sulphate is added to make up the density to mask the watering. The addition of sulphate to milk can be detected by using a qualitative test, like barium chloride test (Sharma et al., 2012 and FSSAI, 2012). The work on possible interference of common preservative in the qualitative test used for detection of adulterants in milk is scanty. However, there is a lacuna of reported work on checking such preservative interference in their detection. Therefore, the efficiency of various tests in the detection of a particular adulterant in the presence of other adulterant, needs to be examined and established. Thus, considering the above problem, the present study was undertaken. 


\section{MATERIAL AND METHODS}

\section{Sulphate}

For detection of sulphate in milk, barium chloride test is used to report by Sharma et al., 2012 and FSSAI, 2012.

\section{Barium Chloride Test}

Test Reported by Sharma et al. (2012) and FSSAI (2012)

Ten $\mathrm{ml}$ of suspected milk sample was taken in a $50 \mathrm{ml}$ stoppered test tube. Then, $10 \mathrm{ml}$ of trichloroacetic acid solution (24\%) was added to coagulate the milk. The coagulated milk was filtered through Whatman filter paper No 42. Further, $5 \mathrm{ml}$ of clear filtrate was taken in the test tube and a few drops of barium chloride solution (5\%) were added. The contents were mixed properly and the formation of any visible precipitates in the tube was observed. The presence of added sulphate like ammonium sulphate, sodium sulphate, zinc sulphate and magnesium sulphate etc. to milk were confirmed, by the formation of milky-white precipitates.

\section{RESULTS AND DISCUSSIONS}

\section{Qualitative Tests for Detection of Sulphate}

Sulphate can be detected in milk, using barium chloride test and for checking the sensitivity of test, the samples of milk varied by addition of sodium sulphate at the rate of $0.00,0.01,0.025,0.05,0.10,0.15$ and 0.20 (g per $100 \mathrm{ml}$ milk). The prepared samples of milk were subjected to barium chloride test, reported in the literature for detection of sulphate. The results obtained for these qualitative tests are presented in Table 1and depicted in Plate 1.

Table 1: LoD in Qualitative Tests for Sulphate in Milk

\begin{tabular}{|c|c|c|c|c|c|c|c|c|}
\hline \multirow{2}{*}{ Sr. No. } & \multirow{2}{*}{ Test } & \multicolumn{7}{|c|}{ Sulphate Added (g/100 ml Milk) } \\
\cline { 3 - 9 } & & $\mathbf{0 . 0 0}$ & $\mathbf{0 . 0 1}$ & $\mathbf{0 . 0 2 5}$ & $\mathbf{0 . 0 5}$ & $\mathbf{0 . 1 0}$ & $\mathbf{0 . 1 5}$ & $\mathbf{0 . 2 0}$ \\
\hline 1 & Barium chloride & $-\mathrm{ve}$ & $?$ & + ve & + ve & + ve & + ve & + ve \\
\hline
\end{tabular}

Sharma et al. (2012) and FSSAI (2012), suggested 0.05 percent LoD for barium chloride test, used to detect sulphate in milk. In present study, 0.025 percent LoD was found for barium chloride test. Thus, LoD for barium chloride test found in present study was lower than the reported LoD in literature. The variation in LoD found in present study may be attributed to variation in composition of milk, variation in purity of reagents, variation in judgement of colour from person to person and other chemical compositional aspects. For detection of sulphate in milk the barium chloride test is the only test reported in the literature, therefore, this test was selected for further study. 


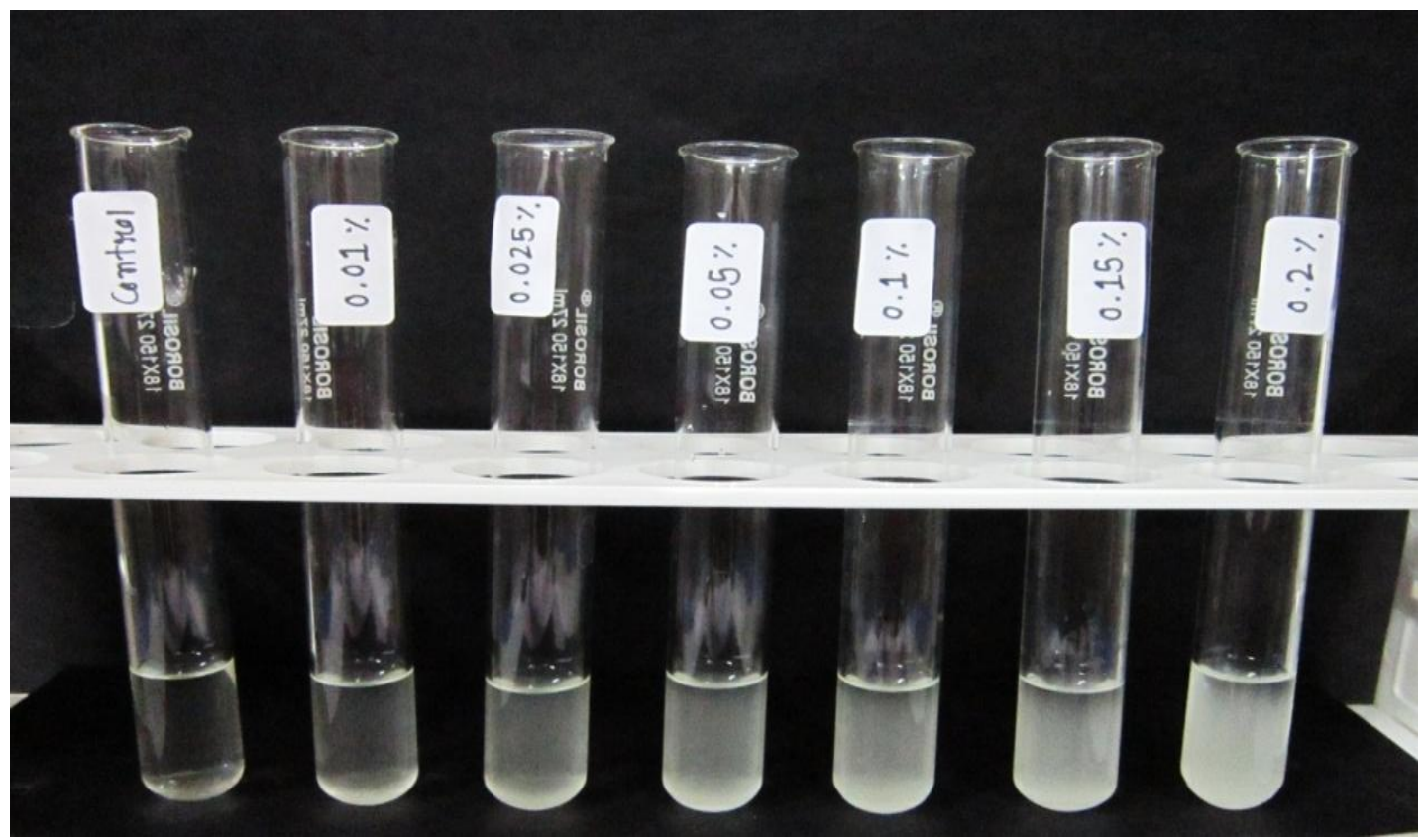

Plate 1: LoD in Qualitative Tests for Sulphate in Milk

Effect of Common Preservatives on Barium Chloride Test Used for Detection of Sulphate

The effect of hydrogen peroxide, formaldehyde and sodium hydroxide on detection of sulphate of barium chloride test was examined.

\section{Effect of Hydrogen Peroxide on Barium Chloride Test for Detection of Sulphate}

The sulphate was added at the rate of 1.25 times the LoD, for sample preparation. The higher amount than the actual LoD was preferred to rule out in any marginal variations in concentration of the adulterant. The sample without addition of any adulterant or preservative was kept as negative control. The sample added with adulterant to be detected, but without addition of any preservative was kept as positive control. Hydrogen peroxide and sodium hydroxide were added separately at the rate of $0.01 \%, 0.02 \%, 0.04 \%, 0.06 \%, 0.08 \%$ and 0.10 per cent, whereas formalin was added at the rate of $0.1 \%, 0.2 \%, 0.4 \%, 0.6 \%, 0.8 \%$ and 1.0 percent along with individual adulterant. The samples of milk, so prepared were subjected to detection of adulterant by employing the selected qualitative test. The results obtained for effect of hydrogen peroxide on the performance of barium chloride test for detection of sulphate in milk is given in table 2 and depicted in plate 2 .

Table 2: Effect of Hydrogen Peroxide on Detection of Sulphate in Milk by Barium Chloride Test

\begin{tabular}{|c|c|c|c|}
\hline Sr. No & Sample & Observation & Inference \\
\hline 1 & Control & Clear solution & \\
\hline 2 & Only sulphate & White precipitate & \\
\hline 3 & Milk with sulphate $+\mathrm{H}_{2} \mathrm{O}_{2}(0.01 \%)$ & White precipitate & \multirow{6}{*}{ No interference } \\
\hline 4 & Milk with sulphate $+\mathrm{H}_{2} \mathrm{O}_{2}(0.02 \%)$ & White precipitate & \\
\hline 5 & Milk with sulphate $+\mathrm{H}_{2} \mathrm{O}_{2}(0.04 \%)$ & White precipitate & \\
\hline 6 & Milk with sulphate $+\mathrm{H}_{2} \mathrm{O}_{2}(0.06 \%)$ & White precipitate & \\
\hline 7 & Milk with sulphate $+\mathrm{H}_{2} \mathrm{O}_{2}(0.08 \%)$ & White precipitate & \\
\hline 8 & Milk with sulphate $+\mathrm{H}_{2} \mathrm{O}_{2}(0.10 \%)$ & White precipitate & \\
\hline
\end{tabular}




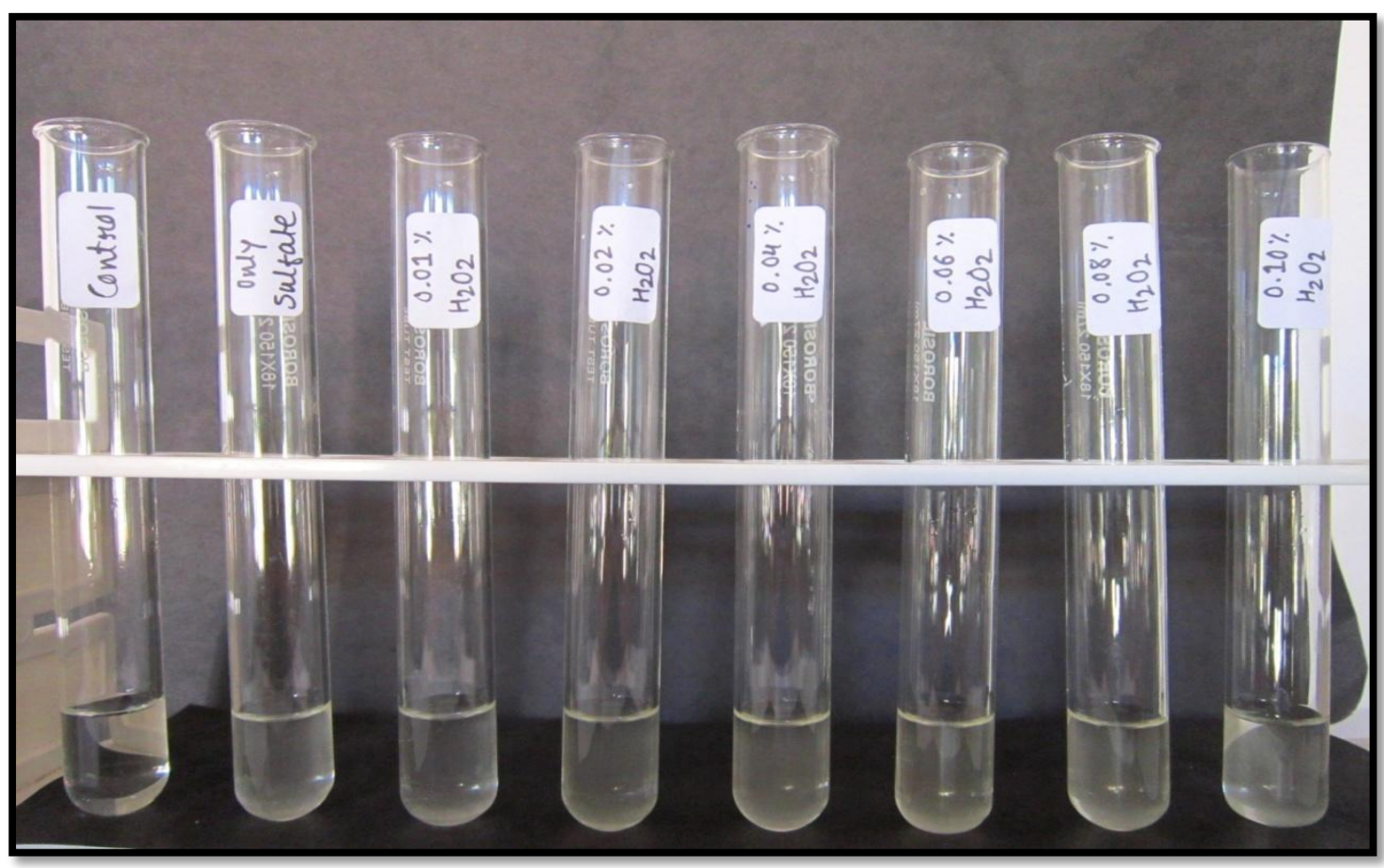

Plate 2: Effect of Hydrogen Peroxide on Detection of Sulphate in Milk by Barium Chloride Test

The results indicated that, hydrogen peroxide had no interference in the detection of sulphate of barium chloride test.

\section{Effect of Formaldehyde on Barium Chloride Test for Detection of Sulphate}

The results obtained for effect of formaldehyde on the performance of barium chloride test for detection of sulphate in milk is given in table 3 and depicted in plate 3.

Table 3: Effect of Formaldehyde on Detection of Sulphate in Milk by Barium Chloride Test

\begin{tabular}{|c|l|l|l|}
\hline Sr. No. & \multicolumn{1}{|c|}{ Sample } & \multicolumn{1}{|c|}{ Observation } & \multirow{2}{*}{ Inference } \\
\hline 1 & Control & Clear solution & \\
\hline 2 & Only sulphate & White precipitate & \\
\hline 3 & Milk with sulphate + Formalin $(0.10 \%)$ & White precipitate & \multirow{3}{*}{ No } \\
\cline { 1 - 3 } 4 & Milk with sulphate + Formalin $(0.20 \%)$ & White precipitate & \\
\hline 5 & Milk with sulphate + Formalin $(0.40 \%)$ & White precipitate & \\
\hline 6 & Milk with sulphate + Formalin $(0.60 \%)$ & White precipitate & \\
\hline 7 & Milk with sulphate + Formalin $(0.80 \%)$ & White precipitate & \\
\hline 8 & Milk with sulphate + Formalin $(1.00 \%)$ & White precipitate & \\
\hline
\end{tabular}




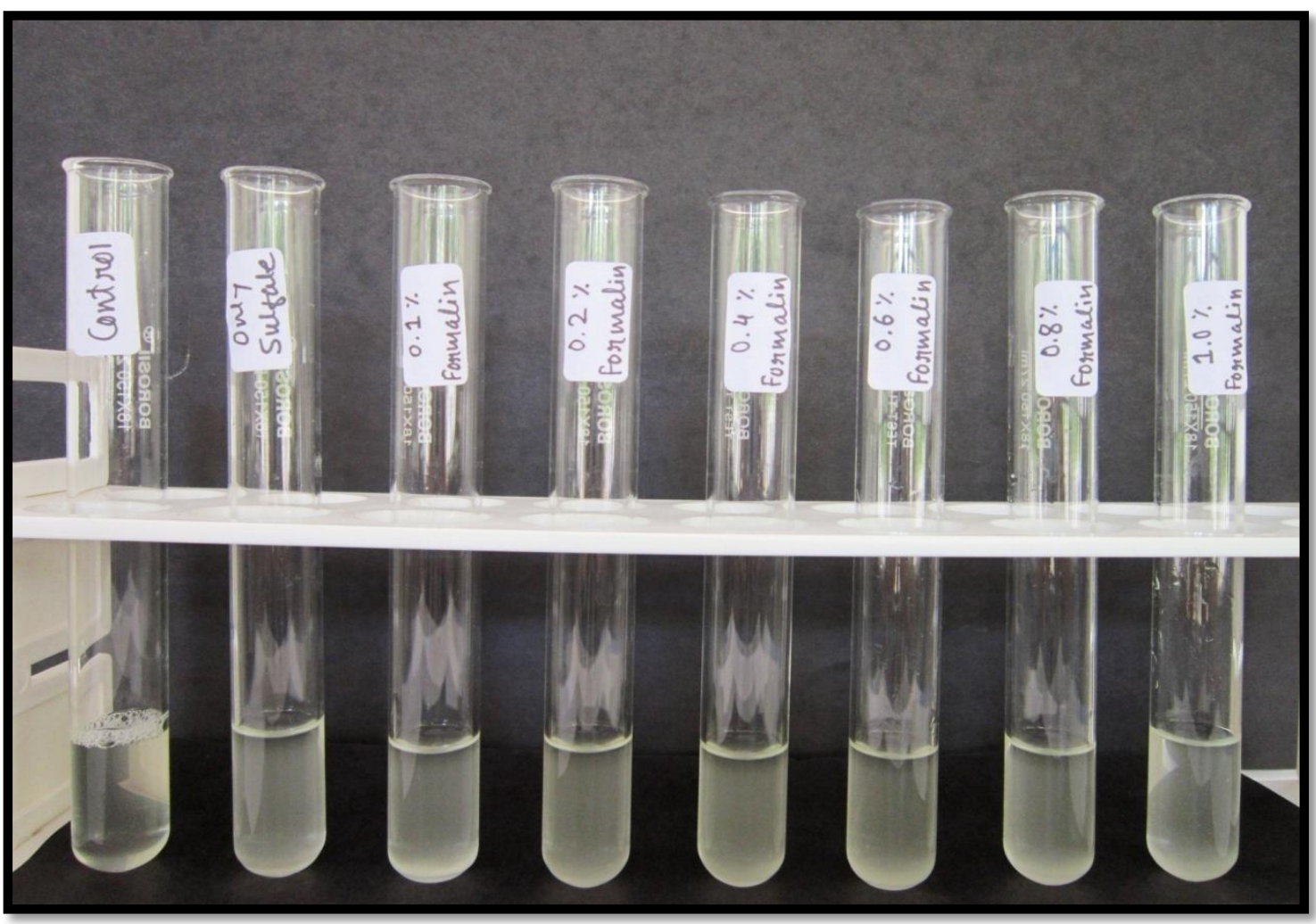

Plate 3: Effect of Formaldehyde on Detection of Sulphate in Milk by Barium Chloride Test

The results indicated that, formaldehyde had no interference in the detection of sulphate of barium chloride test.

\section{Effect of Sodium Hydroxide on Barium Chloride Test for Detection of Sulphate}

The results obtained for effect of sodium hydroxide on performance of barium chloride test, for detection of sulphate in milk is given in table 4 and depicted in plate 4.

Table 4: Effect of Sodium Hydroxide on Detection of Sulphate in Milk by Barium Chloride Test

\begin{tabular}{|c|l|l|l|}
\hline Sr. No. & \multicolumn{1}{|c|}{ Sample } & \multicolumn{1}{|c|}{ Observation } & \multirow{2}{*}{ Inference } \\
\hline 1 & Control & Clear solution & \\
\hline 2 & Only sulphate & White precipitate & \\
\hline 3 & Milk with sulphate $+\mathrm{NaOH}(0.01 \%)$ & Less white precipitate & \multirow{2}{*}{ Interference } \\
\hline 4 & Milk with sulphate $+\mathrm{NaOH}(0.02 \%)$ & Less white precipitate & \\
\hline 5 & Milk with sulphate $+\mathrm{NaOH}(0.04 \%)$ & Less white precipitate & \\
\hline 6 & Milk with sulphate $+\mathrm{NaOH}(0.06 \%)$ & Less white precipitate & \\
\hline 7 & Milk with sulphate $+\mathrm{NaOH}(0.08 \%)$ & Less white precipitate & \\
\hline 8 & Milk with sulphate $+\mathrm{NaOH}(0.10 \%)$ & Less white precipitate & \\
\hline
\end{tabular}




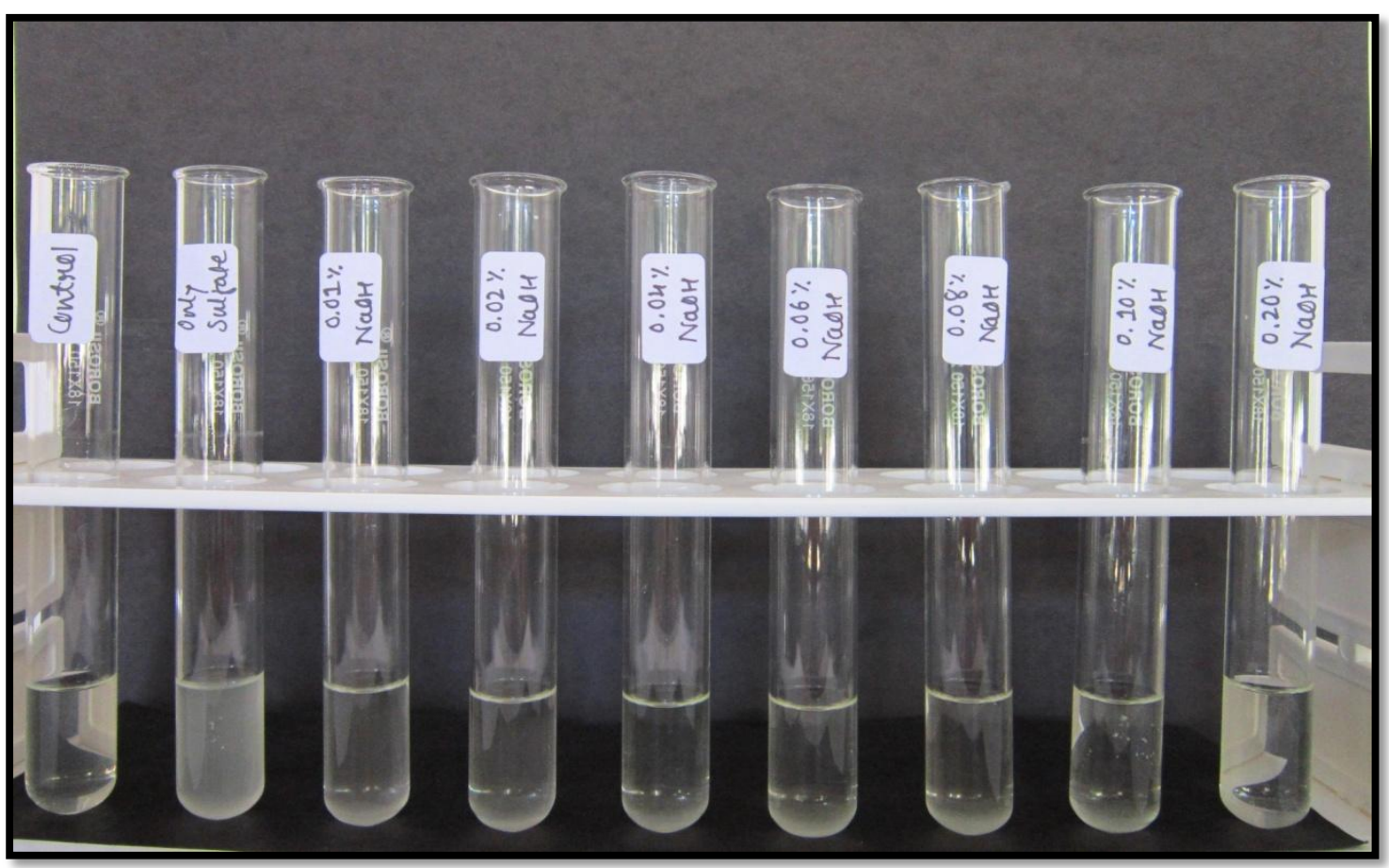

Plate 4: Effect of Sodium Hydroxide on Detection of Sulphate in Milk by Barium Chloride Test

The result indicated that, the presence of sodium hydroxide had a negative effect on detection of sulphate. The positive control had sufficient amount of precipitate to give a turbid appearance as a clear indication of the presence of sulphate. Upon addition of sodium hydroxide the turbidity became very faint and the test resulted into doubtful category. The possible mechanism might be due to neutralization of the acid in the reaction medium. This effect may be attributed due to shift of $\mathrm{pH}$ towards the alkaline side which is evident from the data shown table 5 .

Table 5: Effect of Addition of Sodium Hydroxide on pH of Milk

\begin{tabular}{|c|c|}
\hline Concentration of Formalin $(\% \mathbf{w} / \mathbf{v})$ & $\mathbf{p H}$ of Milk \\
\hline 0.0 & 6.71 \\
\hline 0.01 & 6.83 \\
\hline 0.02 & 7.21 \\
\hline 0.04 & 7.86 \\
\hline 0.06 & 8.02 \\
\hline 0.08 & 8.83 \\
\hline 0.10 & 9.51 \\
\hline
\end{tabular}

\section{CONCLUSIONS}

In the present investigation work was carried out on different qualitative tests used for detection of adulterants in milk. The work included (1) evaluation of barium chloride test used for their sensitivity (LoD) in the detection of a sulphate adulterant, and (2) testing the interference of common preservatives, in the detection of adulterants in milk. The results obtained in the study are summarized and concluded below.

\section{Detection of Sulphate}

For detection of sulphate in milk the barium chloride test is the only test reported in the literature, therefore, this test was selected for further study. No variation was reported in literature for barium chloride test. The interference of hydrogen peroxide, formaldehyde or sodium hydroxide on detection of sulphate of barium chloride test was examined. The 
result indicated that the presence of sodium hydroxide had a negative effect on detection of sulphate. The positive control had sufficient amount of precipitate to give a turbid appearance as a clear indication of the presence of sulphate. Upon addition of sodium hydroxide the turbidity became very faint and the test resulted into doubtful category.

\section{REFERENCES}

1. FSSAI (2012). Manual of methods of analysis of foods (milk and milk products) - A Laboratory Manual. Food safety and standards authority of India, Ministry of health and family welfare, Government of India, New Delhi.

2. Sharma R., Rajput Y.S., Barui A.K. and Laxmana N.N. (2012). Detection of Adulterants in Milk - A Laboratory Manual, Edition-1. NDRI Publication No: 88/2012. National Dairy research Institute, Karnal-132001.

3. Wilhelmsen E. C. (2004). Food adulteration. In: Handbook of Food Analysis. Nollet L.M.L. (ed).Marcel Dekker, Inc. Madison Avenue, New York. pp.2031-2033.

4. Schieber A. (2008). Introduction to food authentication. In "Modern Techniques for Food Authentication" (D.-W. Sun Ed.).Elsevier, 30 Corporate Drive, Suite 400, Burlington, MA 01803, USA. PP 1-27.

5. FSSAI (2011). Executive summary on national survey on milk adulteration. Food Safety and Standards Authority of India. Cited from http://www.fssai.gov.in/portals/0/pdf/sample_analysed(02-01-2012).pdf(05-10-2014). 

